\title{
ВЛИЯНИЕ РАЗЛИЧНЫХ ВИДОВ СЪЕМНЫХ КОНСТРУКЦИЙ И ДЕНТАЛЬНЫХ ИМПЛАНТАТОВ НА МИКРОБИОЦЕНОЗ ПОЛОСТИ РТА ПРИ ОРТОПЕДИЧЕСКОМ ЛЕЧЕНИИ
}

В. П. Тлустенко, И. М. Байриков, Д. А. Трунин, С. С. Комлев, А. В. Жестков, А. В. Лямин

Самарский государственный медицинский университет, Самара, Россия

Проблема осложнений, возникающих после проведения дентальной имплантации, остается актуальной. Целью работы было исследовать влияние различных видов съемных конструкций и дентальных имплантатов на микробиоценоз полости рта при ортопедическом лечении 64 человек: 12 пациентов 1-й основной группы, 40 пациентов 2-й основной группы и 12 человек группы контроля. Через 6 месяцев после установки имплантатов в результате микробиологического исследования полости рта были выявлены различия в качественном составе микрофрлоры слизистой оболочки вокруг шейки дентального имплантата. В основной группе 1 преобладали представители нормальной микрофрлоры. В 100\% случаев выделен Streptococcus vestibularis, более чем у половины пациентов выделены S. oralis, S. mitis, Rothia mucilaginosa, S. gordoniї выделен у одного пациента. В основной группе 2 отмечено значительное разнообразие видов микроорганизмов, включая энтеробактерии, которые были выделены у 22,5\% обследованных. В контрольной группе помимо представителей нормальной микрофлоры слизистой оболочки полости рта обнаружены S. vestibularis (75,5\%), S. oralis (50,0\%), Neisseria subflava (66,7\%) и Haemophylus parainfluenzae (50,0\%). У всех пациентов контрольной группы были выделены S. gordonii, а также другие виды потенциально патогенных стрептококков - S. anginosus и S. constellatus по 66,7\%. Вид используемых съемных конструкций и дентальных имплантатов влияет на состав микрофлоры полости рта, а, следовательно, на дальнейший прогноз и риск развития осложнений. Съемные ортопедические конструкции с металлическим каркасом и фиксирующими элементами, телескопическими коронками и замковыми креплениями с опорой на разборные дентальные имплантаты менее других видов конструкций изменяют качественный состав микроффлоры слизистой оболочки полости рта вокруг шейки дентального имплантата.

Ключевые слова: микробиоценоз, дентальная имплантация, разборный дентальный имплантат, съемные ортопедические конструкции

Информация о вкладе авторов: В. П. Тлустенко, И. М. Байриков, Д. А. Трунин, С. С. Комлев - разработка концепции и дизайна исследования, хирургическое и ортопедическое лечение пациентов; И. М. Байриков, С. С. Комлев, А. В. Жестков, А. В. Лямин - сбор и обработка материала, микробиологическое исследование клинического материала, статистическая обработка.

Соблюдение этических стандартов: исследование одобрено этическим комитетом Самарского государственного медицинского университета (протокол № 2018/197). Все пациенты подписали информированное согласие на проведение операции дентальной имплантации и ортопедическое лечение и участие в исследовании.

$\triangle$ Для корреспонденции: Сергей Сергеевич Комлев ул. Чапаевская, д. 89, г. Самара, 443099; stomat.ks@mail.ru

Статья получена: 27.01.2019 Статья принята к печати: 08.04.2019 Опубликована онлайн: 17.04.2019

DOI: $10.24075 /$ vrgmu.2019.029

\section{EFFECT OF VARIOUS TYPES OF REMOVABLE APPLIANCES AND DENTAL IMPLANTS ON THE ORAL MICROBIOCENOSIS DURING ORTHOPEDIC TREATMENT}

Tlustenko VP, Bairikov IM, Trunin DA, Komlev SS $\square$, Zhestkov AV, Lyamin AV

Samara State Medical University, Samara, Russia

\begin{abstract}
The problem of complications arising after dental implantation is still relevant. The aim of the work was to investigate the effect of various types of removable appliances and dental implants on the oral microbiocenosis during orthopedic treatment of 64 people: 12 patients of the first index group, 40 patients of the second index group and 12 people of the control group. 6 months after the implants were installed, as a result of a microbiological study of the oral cavity, the differences were found in the qualitative composition of the microflora of the mucous membrane around the neck of the dental implant. In the first index group representatives of normal microflora prevailed. In 100\% of cases Streptococcus vestibularis was isolated, from more than half patients S. oralis, S. mitis, Rothia mucilaginosa were isolated, S. gordonii was isolated from one patient. In the second index group, a significant diversity of microbial species was observed, including enterobacteria, which were isolated from $22.5 \%$ of the examined patients. In the control group, in addition to representatives of the normal microflora of the oral mucosa S. vestibularis (75.5\%), S. oralis (50.0\%), Neisseria subflava (66.7\%) and Haemophylus parainfluenzae (50.0\%) were found. From all patients of the control groups S. gordonii was isolated, as well as the other potentially pathogenic streptococci species, $S$. anginosus and S. constellatus by $66.7 \%$. The type of removable appliances and dental implants used affects the microflora composition of the oral cavity, and, consequently, the further prognosis and the risk of complications. Collapsible dental implant supported removable prosthetic appliances with a metal frame and fixing elements, telescopic crowns and clasps less than other types of prosthetic appliances change the qualitative composition of the microflora of the oral mucosa around the neck of the dental implant.
\end{abstract}

Keywords: microbiocenosis, implantation, collapsible dental implant, removable prosthetic appliances

Author contribution: Tlustenko VP, Bairikov IM, Trunin DA, Komlev SS - concept and research design, surgical and orthopedic treatment of patients; Bairikov IM, Komlev SS, Zhestkov AV, Lyamin AV - collection and processing of material, microbiological investigation of clinical material, statistical processing of results.

Compliance with ethical standards: the study was approved by the Ethics Committee of Samara State Medical University (protocol № 2018/197). All patients signed a voluntary informed consent for the dental implantation operation, orthopedic treatment and participation in the study.

$\triangle$ Correspondence should be addressed: Sergey S. Komlev

Chapayevskaya 89, Samara, 443099; stomat.ks@mail.ru

Received: 27.01.2019 Accepted: 08.04.2019 Published online: 17.04.2019

DOI: $10.24075 /$ brsmu.2019.029

Несмотря на значительные достижения в решении технических вопросов, в современной дентальной имплантологии остается актуальной проблема осложнений после установки дентальных имплантатов [1]. Наиболее часто встречаются мукозиты и периимплантиты, в развитии которых активное участие принимают микроорганизмы, как в норме представленные в полости рта, так и колонизирующие поверхности материалов, из 
которых выполнены дентальные имплантаты и съемные конструкции [2-5].

В литературе описана способность микроорганизмов адгезироваться на поверхности абатментов дентальных имплантатов и съемных ортопедических конструкций. В качестве тестовых микроорганизмов чаще всего оценивают бактерии, которые не являются основополагающими с точки зрения развития патологических процессов, связанных с использованием дентальных имплантатов [6-8].

Дополнительные сложности в оценке микробиоты полости рта при использовании съемных ортопедических конструкций и дентальных имплантатов возникают в результате несовершенства применяемых методов лабораторной диагностики и неправильно построенного дизайна исследований. Как правило, исследователи ограничиваются общей оценкой анаэробной и/или аэробной микрофллоры без учета ее видового разнообразия; использованием только методов, основанных на обнаружении ДНК микроорганизмов представителей патогенных комплексов; в некоторых случаях используют заведомо неприемлемые с точки зрения оценки микрофлоры полости рта методы, например, тест-системы, разработанные для оценки микрофллоры других локусов организма человека [9-11].

Такие подходы могут приводить к получению противоречивых результатов при оценке качественного и количественного составов микрофлоры полости рта, а также затрудняют оценку роли представителей микросрлоры в развитии осложнений, связанных с установкой дентальных имплантатов; качественного и количественного состава микрофлоры при сравнении влияния однотипных ортопедических конструкций, выполненных из различных видов материала. При этом не учитывают факторы патогенности и сложноорганизованную архитектонику взаимодействия различных видов микроорганизмов в колонизации поверхностей дентальных имплантатов и съемных ортопедических конструкций нормальной, патогенной и транзиторной микрофлорой.

Целью работы было оценить влияние использования различных видов дентальных имплантатов на микробиоценоз полости рта.

\section{ПАЦИЕНТЫ И МЕТОДЫ}

Микробиологическое исследование проводили у 64 пациентов с различными видами дентальных имплантатов (22 мужчин и 42 женщин в возрасте 45-65 лет): 12 пациентов основной группы 1, 40 пациентов основной группы 2, 12 человек составили группу контроля. Критерии включения в исследование: наличие односторонних и двусторонних концевых дефектов зубных рядов. Критерии исключения: наличие заболеваний кровеносной системы; наличие онкологических заболеваний.

Сбор и транспортировку биологического материала проводили в соответствии с требованиями МУ 4.2.2039-05 «Техника сбора и транспортирования биоматериалов в микробиологические лаборатории». Образцы материала для микробиологического исследования собирали со слизистой оболочки полости рта вокруг шейки дентального имплантата стерильными ватными тампонами, которые сразу же после сбора помещали в транспортные среды для аэробных и анаэробных микроорганизмов. Транспортировку материала в лабораторию осуществляли в течение 2 ч в изотермических условиях при температуре $22-24{ }^{\circ} \mathrm{C}$.
В лаборатории материал засевали на плотные питательные среды: кровяной агар, универсальную среду для дифференциации ХайХром (HiMedia; Индия), агар для анаэробных микроорганизмов (HiMedia; Индия), селективные среды для выделения стафилококков - маннит-солевой агар (HiMedia; Индия), грибов - агар Сабуро (HiMedia; Индия), энтеробактерий — среда Эндо (HiMedia; Индия), неферментирующих грамотрицательных бактерий цетримидный агар (HiMedia; Индия). Культивирование проводили в аэробных и анаэробных условиях с использованием анаэростатов и газогенерирующих пакетов коммерческого производства BD GasPak ${ }^{\mathrm{TM}}$ EZ Container Systems (BD; США) в течение 48-72 ч при температуре $35-37^{\circ} \mathrm{C}$.

Выделенные микроорганизмы идентифицировали с использованием MALDI-ToF масс-спектрометрии на приборе Microflex LT (MALDI Biotyper 3.1, Bruker Daltonik $\mathrm{GmbH}$; Германия).

Сбор материала проводили через 6 месяцев после ортопедического лечения пациентов. Качественный состав выделенной микрофлоры оценивали с учетом группировки микроорганизмов в зависимости от их потенциального патогенетического воздействия на слизистую оболочку полости рта и костную ткань.

Всего было выделено и идентифицировано 328 штаммов микроорганизмов 26 родов.

Оценку состава микрофлоры слизистой оболочки полости рта вокруг шейки дентального имплантата провели у 64 пациентов. В зависимости от конструкции дентального имплантата и съемной ортопедической конструкции все пациенты, которым проводили микробиологическое исследование, были разделены на три группы.

1. В 1-ю подгруппу основной группы (основная 1) вошли 12 пациентов, которым изготавливали съемные ортопедические конструкции с металлическим каркасом и фиксирующими элементами, использовали телескопические коронки и замковые крепления с опорой на разборные дентальные имплантаты (Патент РФ № 2593349). После операции имплантации и необратимой резорбции костной ткани с предложенной конструкцией имплантата стало возможным отсоединить от остеоинтегрированной апикальной части промежуточную часть и использовать апикальную часть для фиксации абатмента, съемной ортопедической конструкции.

2. Во 2-ю подгруппу основной группы (основная 2) вошли 40 пациентов, которым изготавливали съемные ортопедические конструкции с опорой на серийно выпускаемые дентальные имплантаты, фиксирующие замковые элементы располагались в металлическом каркасе съемного протеза.

3. В контрольную группу вошли 12 пациентов, которым были изготовлены съемные ортопедические конструкции из акриловых пластмасс с опорой на дентальные имплантаты, выпускаемые серийно, фиксирующие элементы располагались в базисе съемной ортопедической конструкции.

\section{РЕЗУЛЬТАТЫ ИССЛЕДОВАНИЯ}

Bce микроорганизмы, колонизирующие слизистые оболочки полости рта, могут обладать определенным патогенным потенциалом, однако у одних он выражен в большей степени, у других реализуется в редких случаях. В связи с этим выделенные микроорганизмы мы условно разделили на представителей нормобиоты 
слизистых оболочек полости рта: Streptococcus salivarius, Streptococcus vestibularis, Streptococcus parasanguinis, Streptococcus oralis, Streptococcus sanguinis, Streptococcus mitis, Rothia dentocariosa, Rothia mucilaginosa, Neisseria macacae, Neisseria subflava, Neisseria flavescens, Haemophilus parainfluenzae, Lactobacillus salivarius, Gemella haemolysans; микрофлору, которая принимает участие в патогенных процессах на различных уровнях: Streptococcus anginosus, Streptococcus gordonii, Streptococcus constellatus; микрофлору, в меньшей степени характерную для слизистой оболочки полости рта, но, как правило, не участвующую в патологических процессах: Acinetobacter junii, Staphylococcus capitis, Staphylococcus epidermidis, Staphylococcus warnerii, Streptococcus pneumoniae; нетипичную для полости рта микрофлору с высоким патогенным потенциалом: Enterobacter cloacae, Citrobacter freundii, Escherichia coli. Отдельную группу составили грибы рода Candida.

При анализе качественного состава микрофлоры слизистой оболочки полости рта вокруг дентального имплантата у пациентов исследуемых групп были получены данные, представленные в таблице.

При анализе полученных данных были выявлены следующие особенности качественного состава микроорганизмов в структуре микробиоценоза слизистой оболочки полости рта вокруг шейки дентального имплантата.

Отличительной особенностью микрофлоры пациентов основной 1-й группы оказалось преобладание нормосрлорь у значительной части обследованных. В 100\% случаев был выделен Streptococcus vestibularis, более чем у половины пациентов были выделены Streptococcus oralis, Streptococcus mitis, Rothia mucilaginosa. В данной группе пациентов не было выделено энтеробактерий и грибов рода Candida. Однако следует отметить достаточно частое выделение сапрофитной микрофлоры, нехарактерной для слизистой оболочки полости рта, которая была обнаружена у половины пациентов.

Основная 2-я группа характеризовалась значительным разнообразием микроорганизмов. У пациентов не было выявлено доминирующей группы микроорганизмов. Тем не менее микрофрлора чаще была представлена нормальными микроорганизмами, характерными для слизистой оболочки полости рта, среди которых преобладал Streptococcus vestibularis. У трети пациентов были выделены микроорганизмы с потенциальным патогенным действием. Но, на наш взгляд, наибольшее значение в этой группе имел факт выделения у 9 пациентов энтеробактерий, нехарактерных для данного локуса и обладающих значительным патогенным потенциалом, как с точки зрения выделения протеолитических ферментов, так и с точки зрения непосредственного участия в развитии инфекционных осложнений различной локализации.

В контрольной группе преобладали Streptococcus vestibularis и Streptococcus oralis, а также Neisseria subflava и Haemophilus parainfluenzae в качестве представителей нормальной микрофлоры ротовой полости. Остальные представители нормофлоры были выделены менее чем у 50\% обследованных из контрольной группы.

Таблица. Качественный состав микрофлоры слизистой оболочки вокруг дентального имплантата (количество штаммов в абсолютных числах и доля штаммов от общего числа микроорганизмов, выделенных в группе)

\begin{tabular}{|c|c|c|c|}
\hline Вид микроорганизмов & Контрольная группа пациентов & Основная 1 & Основная 2 \\
\hline Streptococcus salivarius & $2(16,7 \%)$ & $2(16,7 \%)$ & $12(30,0 \%)$ \\
\hline Streptococcus vestibularis & $9(75,0 \%)$ & $12(100 \%)$ & $24(60,0 \%)$ \\
\hline Streptococcus parasanguinis & 0 & $2(16,7 \%)$ & $8(20,0 \%)$ \\
\hline Streptococcus oralis & $6(50,0 \%)$ & $10(83,3 \%)$ & $12(30,0 \%)$ \\
\hline Streptococcus sanguinis & $3(25,0 \%)$ & 0 & $15(37,5 \%)$ \\
\hline Streptococcus mitis & $4(33,3 \%)$ & $6(50,0 \%)$ & $12(30,0 \%)$ \\
\hline Streptococcus anginosus & $8(66,7 \%)$ & 0 & 0 \\
\hline Streptococcus gordonii & $12(100 \%)$ & $1(8,3 \%)$ & $9(22,5 \%)$ \\
\hline Streptococcus constellatus & $8(66,7 \%)$ & 0 & 0 \\
\hline Streptococcus pneumoniae & $3(25,0 \%)$ & $4(33,3 \%)$ & $4(10,0 \%)$ \\
\hline Rothia dentocariosa & $3(25,0 \%)$ & $2(16,7 \%)$ & $3(7,5 \%)$ \\
\hline Rothia mucilaginosa & 0 & $8(66,7 \%)$ & $18(45,0 \%)$ \\
\hline Neisseria macacae & $3(25,0 \%)$ & 0 & $3(7,5 \%)$ \\
\hline Neisseria subflava & $8(66,7 \%)$ & $2(16,7 \%)$ & $18(45,0 \%)$ \\
\hline Neisseria flavescens & 0 & $2(16,7 \%)$ & $4(10,0 \%)$ \\
\hline Haemophilus parainfluenzae & $6(50,0 \%)$ & $1(8,3 \%)$ & $8(20,0 \%)$ \\
\hline Lactobacillus salivarius & $2(16,7 \%)$ & $4(33,3 \%)$ & $3(7,5 \%)$ \\
\hline Gemella haemolysans & 0 & $2(16,7 \%)$ & $4(10,0 \%)$ \\
\hline Acinetobacter junii & 0 & $1(8,3 \%)$ & 0 \\
\hline Staphylococcus capitis & 0 & $2(16,7 \%)$ & 0 \\
\hline Staphylococcus epidermidis & $4(33,3 \%)$ & $2(16,7 \%)$ & $8(20,0 \%)$ \\
\hline Staphylococcus warnerii & $3(25,0 \%)$ & $2(16,7 \%)$ & 0 \\
\hline Enterobacter cloacae & 0 & 0 & $6(15,0 \%)$ \\
\hline Citrobacter freundii & 0 & 0 & $2(5,0 \%)$ \\
\hline Escherichia coli & 0 & 0 & $1(2,5 \%)$ \\
\hline Candida albicans & $4(33,3 \%)$ & 0 & 0 \\
\hline
\end{tabular}


Отличительной особенностью микросрлоры у пациентов контрольной группы оказалось широкое распространение микроорганизмов, имеющих большое значение в качестве триггеров в колонизации патогенной микрофлорой. У всех пациентов контрольной группы был выделен Streptococcus gordonii, обладающий повышенной адгезивной способностью, которая реализуется микроорганизмами с выраженным патогенным потенциалом. Кроме того, более чем у половины пациентов контрольной группы были выделены Streptococcus anginosus и Streptococcus constellatus. Только в контрольной группе были выделены грибы рода Candida, представленные у всех пациентов единственным видом - Candida albicans (были выделены у одной трети пациентов).

Таким образом, у пациентов основной 1-й группы проведенное имплантологическое лечение с использованием разборных дентальных имплантатов и ортопедическое лечение характеризуются наименьшим изменением качественного состава микрофлоры слизистой оболочки полости рта вокруг шейки дентального имплантата. Следует отметить, что у пациентов всех групп не было выделено представителей «красного» парадонтопатогенного комплекса.

Кроме качественного состава была проанализирована частота выделения микроорганизмов по группам и родам с учетом потенциального участия их в патологическом процессе. В связи со значительным влиянием некоторых видов стрептококков в патогенных процессах было принято решение разделить их на две группы: «имеющие потенциальное патогенное значение» и «представители нормослоры».

Данные по частоте выделения у пациентов представителей различных групп микроорганизмов представлены на рис. 1.

Были выявлены следующие особенности микросрлоры. В основной 1-й группе при анализе частоты выделения представителей различных групп микроорганизмов было выявлено значительное преобладание нормальной микрофлоры, представленной стрептококками, лактобактериями, представителями родов Rothia, Gemella. Условно патогенные нейссерии встречались несколько реже, чем в контрольной группе, также меньше были распространены стафилококки.

В основной 2-й группе по частоте встречаемости лидировали стрептококки - представители нормальной микрофрлоры, нейссерии, а также бактерии из рода Rothia. Однако следует отметить, что это единственная группа пациентов, у которых были выделены энтеробактерии.

В контрольной группе у 100\% обследованных были обнаружены стрептококки с потенциальным патогенным потенциалом, что, безусловно, может оказывать неблагоприятное влияние с точки зрения рисков развития осложнений в ранний период после установки имплантата. Стрептококки - представители нормофлоры были выделены более чем у 70\% пациентов. Отмечено снижение частоты выделения других представителей нормальной микрофлоры, которые были выявлены менее чем у 50\% обследованных из контрольной группы, за исключением представителей рода Neisseria. Как было описано выше, у одной трети пациентов были выделены грибы рода Candida.

\section{ОБСУЖДЕНИЕ РЕЗУЛЬТАТОВ}

При анализе частоты распространения представителей различных групп микроорганизмов на слизистой оболочке полости рта вокруг шейки дентального имплантата были выявлены определенные закономерности. В контрольной группе преобладали микроорганизмы, обладающие потенциальным патогенным действием, характеризующиеся повышенной адгезивной активностью, а также грибы рода Candida, что возможно связано с особенностями расположения фиксирующих элементов в базисе акриловых протезов с опорой на кобальтохромовые абатменты серийных дентальных имплантатов. Отсутствие осложнений у пациентов, включенных в исследование, связано с тем, что наряду с потенциально агрессивной микрофлорой в контрольной группе достаточно широко были распространены представители и нормальной микрофлоры. В основной 1 группе были выявлены оптимальные микробиологические соотношения, как по качественному составу микрофлоры, так и по частоте высева нормальных обитателей микробиоты слизистой оболочки полости рта. В данной группе была наименьшей частота выделения стрептококков с потенциальным патогенным действием, не было высева кандид и энтеробактерий. Основная 2 группа характеризовалась максимальным разнообразием как качественного состава, так и частоты выделения различных групп

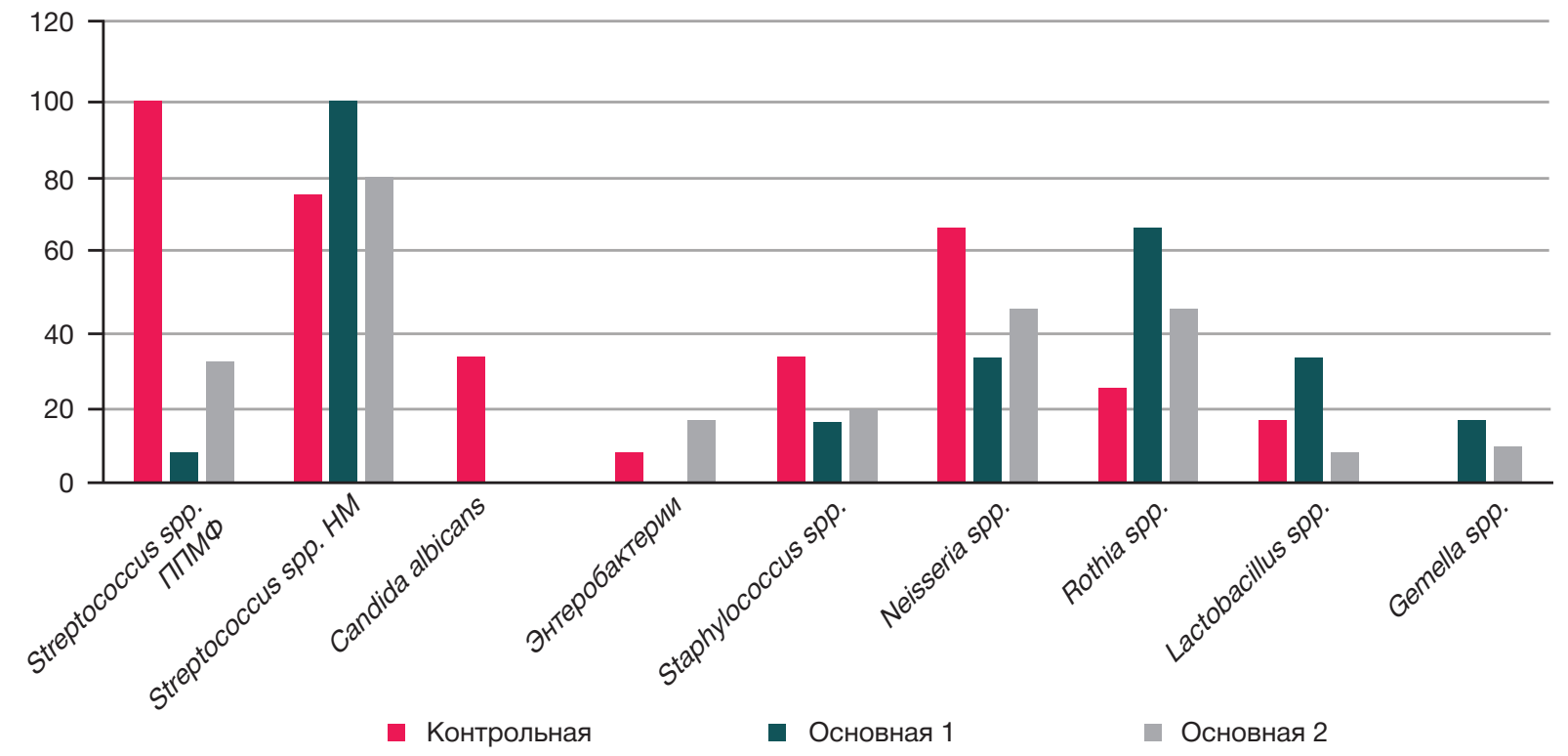

Рис. 1. Частота выделения микроорганизмов у пациентов различных групп (\%). ППМФ — потенциальная патогенная микрофлора, НМ — нормальная микрофлора 
микроорганизмов. Наряду с нормальной микрофлорой были выделены стрептококки с потенциальным патогенным действием, а также энтеробактерии, что, на наш взгляд, представляет наибольшую угрозу с точки зрения формирования постимплантационных осложнений [4, 7, 9-11].

Следует отметить, что практически все микроорганизмы, обладающие патогенным потенциалом, были выделены в строгих анаэробных условиях, что может быть косвенным признаком их активного участия в процессе адаптации к измененным условиям на слизистых оболочках вокруг шейки дентального имплантата. Значительные изменения в качественном составе микрофлоры и в частоте выделения различных групп микроорганизмов среди пациентов контрольной и основных групп демонстрируют необходимость тщательного подбора конструкции дентального имплантата, абатмента, съемной ортопедической конструкции. Основными целями в данном случае являются минимизация негативного воздействия «инородного» объекта (дентального имплантата) на межмикробные взаимодействия, способные привести к доминированию в микробиоценозе микроорганизмов с выраженными адгезивными свойствами, обладающими потенциальным патогенным действием, а также исключение колонизации слизистых оболочек транзиторной микрофрлорой с высоким патогенным потенциалом, которая может стать триггером в развитии мукозитов и периимплантитов. Негативное влияние имплантатов было подтверждено данными, полученными в ходе исследования: преобладанием микроорганизмов с высоким адгезивным потенциалом среди пациентов контрольной группы; большим разнообразием транзиторной микрофрлоры и энтеробактерий в основной 2-й группе.

Микрофрлора полости рта является сложноорганизованной ассоциацией микроорганизмов, на качественный и количественный составы которой влияют различные экзогенные и эндогенные факторы. Протезирование с использованием съемных ортопедических конструкций с опорой на дентальные имплантаты неизбежно воздействует на микробиоту слизистых оболочек. Данные изменения могут быть условно «нейтральны» с точки зрения преобладающих групп микроорганизмов, а могут приводить к значительным изменениям в составе микрофлоры, при котором представителей нормальной микробиоты будут вытеснять транзиторные микроорганизмы, количество которых значительно возрастает на слизистых оболочках полости рта по причине использования съемных ортопедических конструкций.

Необходимо отметить, что материал, из которого выполнены абатменты дентальных имплантатов, механизмы крепления и съемные ортопедические конструкции могут влиять на перераспределение превалирующих групп микроорганизмов, увеличивая количество бактерий и грибов с повышенными адгезивными свойствами в популяции микроорганизмов на поверхности абатмента дентального имплантата и на слизистых оболочках полости рта, которая имеет непосредственный контакт с ними. Такие изменения могут длительное время оставаться субкомпенсированными за счет адаптационных механизмов выживания бактерий в биопленках, но рано или поздно будут приводить к накоплению патогенного потенциала микроорганизмов, изменению качественного состава микрофлоры, колонизирующей шейку дентального имплантата и слизистую оболочку полости рта вокруг нее. Вовлечение в процесс сначала потенциально патогенных стрептококков, к которым можно отнести Streptococcus gordoni и ряд других, выделенных у пациентов контрольной группы, микроорганизмов неизбежно приведет к повышению адгезивной способности других микроорганизмов, в частности с доказанным патогенным действием, что подтверждается данными, описанными В научной литературе [4, 7, 9]. Вовлечение в процесс колонизации и смены доминирующей микробной популяции энтеробактерий, стасилококков, грибов можно расценивать в качестве серьезного фактора риска развития постимплантационных осложнений.

\section{ВЫВОДЫ}

Имплантологический и ортопедический виды лечения, проведенные пациентам основной 1-й группы, с использованием съемных конструкций с металлическим каркасом и фиксирующими элементами, телескопических коронок и замковых креплений с опорой на разборные дентальные имплантаты (Патент РФ № 2593349) меньше изменяло качественный состав микрофлоры слизистой оболочки полости рта вокруг шейки дентального имплантата по сравнению с другими методами ортопедического лечения. У данной группы пациентов в небольшом количестве была выявлена микрофлора, участвующая в адгезии парадонтопатогенных микроорганизмов к слизистым оболочкам полости рта, снижающей риск развития периимплантитов.

Полученные в исследовании данные свидетельствуют о влиянии вида ортопедических конструкций и дентальных имплантатов на микробиоценоз полости рта. Дальнейшие исследования в этой области позволят минимизировать негативное воздействие ортопедического лечения на качественный состав микрофлоры полости рта, снизить риск осложнений, развития мукозитов и периимплантитов.

\section{Литература}

1. Гветадзе Р. Ш., Узунян Н. А., Лебеденко И. Ю. и др. Остеоинтеграция сверхупругих сплавов титана и ниобия. В сборнике: Актуальные вопросы стоматологии. Сборник научных трудов, посвященный основателю кафедры ортопедической стоматологии КГМУ профессору Исааку Михайловичу Оксману, Казань. 2018; 89-93.

2. Тлустенко В. П., Тлустенко В. С., Головина Е. С., Кошелев В. А. Влияние хронического локализованного пародонтита и дентального периимплантита на гомеостаз полости рта. Здоровье и образование в XXI веке. 2017; 19 (11): 102-6.
3. Утюж А. С., Юмашев А. В., Михайлова М. П. Ортопедические конструкции из сплавов титана при непереносимости традиционных зубных протезов. Врач. 2016; (7): 62-4.

4. Горобец С. М., Романенко И. Г., Джерелей А. А. и др. Факторы риска развития воспалительных осложнений дентальной имплантации. Таврический медико-биологический вестник. 2017: 20 (2): 208-14.

5. Alkan EA, Tüter G, Parlar A, et al. Evaluation of peri-implant crevicular fluid prostaglandin levels in augmented extraction sockets by different biomaterials. Acta Odontol. Scand. 2016; 74 (7): 532-8. 
6. Саливончик М. С., Каливраджиян Э. С., Рыжова И. П. Результаты микроскопии базисных полимеров. Современная ортопедическая стоматология. 2014; (22): 66-7.

7. Рыжова И. П., Присный А. А., Шинкаренко Н. Н., Саливончик М. С. Состояние микрофлоры полости рта под влиянием съемных конструкций зубных протезов. Международный журнал прикладных и фундаментальных исследований. 2014; (2): 151-3.

8. Riega-Torres JC, Villarreal-Gonzalez AJ, Ceceñas-Falcon LÁ, Salas-Alanis JC. Sjögren's syndrome (SS), a review of the subject and saliva as a diagnostic method. Gac Med Mex. 2016; 152 (3): 371-80.

9. Хабилов Н. Л., Акбаров А. Н., Салимов О. Р. и др. Влияние

\section{References}

1. Gvetadze RSh, Uzunjan NA, Lebedenko lyu, et al. Osseointegration of superelastic alloys of titanium and niobium. In the collection: Actual issues of dentistry Collection of scientific papers dedicated to the founder of the Department of Prosthetic Dentistry KSMU Professor Isaak M. Oksman, Kazan. 2018; 89-93.

2. Tlustenko VP, Tlustenko VS, Golovina ES, Koshelev VA. Effect of chronic localized periodontitis and dental periimplantitis on ora homeostasis. Journal of Scientific Articles Health and Education in the XXI Century. 2017; 19 (11): 102-6.

3. Utjuzh AS, Jumashev AV, Mihajlova MP. Prosthetic appliances made of titanium alloys with intolerance to traditional dentures. Doctor. 2016; (7): 62-64.

4. Gorobec SM, Romanenko IG, Dzherelej AA, et al. Risk factors for the development of inflammatory complications after the implantation. Tavrichesky Medical-Biological Journal. 2017; 20 (2): 208-14.

5. Alkan EA, Tüter $\mathrm{G}$, Parlar $\mathrm{A}$, et al. Evaluation of peri-implan crevicular fluid prostaglandin levels in augmented extraction sockets by different biomaterials. Acta Odontol. Scand. 2016; 74 (7): 532-8.

6. Salivonchik MS, Kalivradzhiyan ES, Ryzhova IP. Results of съемных пластиночных протезов на микробиоценоз полости рта. Medicus. 2016; 6 (12): 82-5.

10. Зекий А. О., Зекий О. Е. Патогенная микросрлора и состояние периимплатационных тканей у пациентов с несъемными ортопедическими конструкциями с опорой на внутрикостные имплантаты при использовании герметизирующей силиконовой матрицы. Институт стоматологии. 2018; (1): 37-9.

11. Шишкова Ю. С., Бабикова М. С., Орнер И. Ю. и др. Особенности микробного спектра ротовой жидкости лиц, использующих стоматологические ортопедические конструкции. Медицинская наука и образование Урала. 2017; 1 (89): 32-6.

microscopy of basic polymers. Modern prosthetic dentistry. 2014 (22): 66-7.

7. Ryzhova IP, Prisnyj AA, Shinkarenko NN, Salivonchik MS. The state of the oral microflora under the influence of removable dentures. Intern journals applied and basic research. 2014; (2): 151-3.

8. Riega-Torres JC, Villarreal-Gonzalez AJ, Ceceñas-Falcon LÁ, Salas-Alanis JC. Sjögren's syndrome (SS), a review of the subject and saliva as a diagnostic method. Gac Med Mex. 2016; 152 (3): 371-80.

9. Habilov NL, Akbarov AN, Salimov OR, et al. Influence of removable laminar prostheses on the oral microbiocenosis. Medicus. 2016; 6 (12): 82-5.

10. Zekij AO, Zekij OE. Pathogenic microflora and the state of periimplantable tissues in patients with fixed prosthetic appliances with support on intraosseous implants using a silicone sealing matrix. Institute of Dentistry. 2018; (1): 37-9.

11. Shishkova YuS, Babikova MS, Orner lyu, et al. Features of the microbial spectrum of the oral fluid of persons using dental prosthetic appliances. Medical science and education of the Urals. 2017; 1 (89): 32-6. 